\title{
Anti-leishmania antibodies in cerebrospinal fluid from dogs with visceral leishmaniasis
}

\section{V.M.F. Lima, M.E. Gonçalves, \\ F.A. Ikeda, M.C.R. Luvizotto and M.M. Feitosa}

\author{
Departamento de Clínica, Cirurgia e Reproducão Animal, \\ Faculdade de Medicina Veterinária de Araçatuba, \\ Universidade Estadual Paulista, Araçatuba, SP, Brasil
}

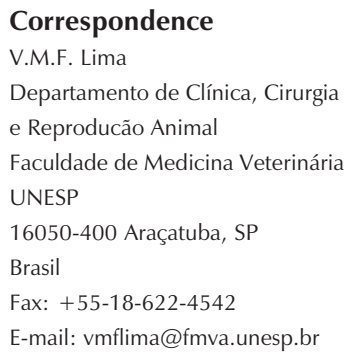

Presented at the XVII Annual Meeting of the Federação de Sociedades de Biologia Experimental, Salvador, BA, Brazil, August 28-31, 2002.

Publication supported by FAPESP. Publication suppoid by FAPSP.

Received April 11, 2002 Accepted December 12, 2002

\begin{abstract}
Visceral leishmaniasis in Brazil is caused by Leishmania (Leishmania) chagasi and the dog is its most important reservoir. The clinical features in dogs include loss of weight, lymphadenopathy, renal failure, skin lesions, fever, hypergammaglobulinemia, hepatosplenomegaly, anemia, and, rarely, neurological symptoms. Most infected animals develop active disease, characterized by high anti-leishmania antibody titers and depressed lymphoproliferative ability. Antibody production is not primarily important for protection but might be involved in the pathogenesis of tissue lesions. An ELISA test was used to determine if there is an association between neurological symptoms and the presence of anti-L. chagasi antibodies in cerebrospinal fluid (CSF). Thirty serum and CSF samples from symptomatic mixed breed dogs (three with neurological symptoms) from a region of high incidence of visceral leishmaniasis in Brazil were examined for antibody using total parasite antigen and anti-dog IgG peroxidase conjugate. A high level of $L$. chagasi antibodies was observed in sera (mean absorbance $\pm \mathrm{SD}, 1.939 \pm 0.405$; negative control, $\mathrm{N}=20,0.154 \pm$ $0.074)$ and $\operatorname{CSF}(1.571 \pm 0.532$; negative control, $\mathrm{N}=10,0.0195 \pm$ 0.040 ) from all animals studied. This observation suggests that $L$. chagasi can cause breakdown of filtration barriers and the transfer of antibodies and antigens from the blood to the CSF compartment. No correlation was observed between antibody titer in CSF and neurological symptoms.
\end{abstract}

Parasitic protozoa of the genus Leishmania are the causative agents of a wide spectrum of diseases, namely, cutaneous, mucocutaneous and visceral leishmaniasis. Zoonotic visceral leishmaniasis caused by both Leishmania infantum and L. chagasi corresponds to $20 \%$ of the cases of human visceral leishmaniasis in the world $(100,000$ cases annually) and its incidence is growing in
Key words

- Leishmania

(Leishmania) chagasi

- Visceral leishmaniasis

- Cerebrospinal fluid

- Dogs

- Antibodies urban and periurban areas of the tropics (1). Dogs constitute the main domestic reservoir of this parasite and play a central role in the transmission cycle of the parasite to humans by phlebotomine sandflies.

Most of the infected animals are susceptible and develop active disease, which is characterized by high anti-leishmania antibody titers and depressed lymphoprolifera- 
tive abilities (2). Antibody production is not primarily important for protection but might be involved in the pathogenesis of tissue lesions. High levels of immune complexes play an important role in many disease processes, i.e., various forms of glomerulonephritis (3), arthritis (4), vasculitis (5), and uveitis (6).

The canine disease is a chronic debilitating condition accompanied by skin lesions, dermatitis, generalized lymphadenopathy, keratoconjunctivitis, diarrhea and an acceleration in nail growth resulting in long curled claws. Typical severe cases also show a marked loss of weight and muscles (7).

The parasite has been reported to be capable to invade various types of tissue such as the spleen and lymph nodes (8), the skin (9) and also other ones such as the lung (10), the intestine (11) and, more recently, the choroid plexus (12). The migration of parasites to the cerebrospinal fluid (CSF) has been reported in humans (13).

Dogs naturally infected with $L$. infantum showed anti-leishmania IgG in CSF. The interstitial and intravascular deposition of IgG and leishmania antigens in the choroid plexus may predispose to the pathological sponge-like reaction accompanied by neuronal degeneration and mobilization of glial cells together with accumulation of amyloid deposits (14).

The spreading of infection to brain tissue could lead to the development of canine cerebral leishmaniasis, which is characterized by alterations in the CSF and by the frequent association of the disease with neurological symptoms (15).

We investigated whether a high level of L. chagasi antibody in CSF is correlated with neurological symptoms. Thirty symptomatic, naturally infected L. chagasi-positive, mixed breed dogs showed numerous symptoms compatible with visceral leishmaniasis, such as febrile syndrome, cachexia, and enlargement of lymph nodes. Three animals from this group also showed associated neurological symptoms, such as seizures, ataxia, and paralysis. The presence of amastigote forms of the parasite in macrophages from popliteus and prescapular lymph nodes was confirmed in all animals. After an intravenous injection of $25 \mathrm{mg} / \mathrm{kg}$ of thiopental (12.5\% Thionembutal) into each animal, several samples were taken: $5 \mathrm{ml}$ of serum, frozen at $-20^{\circ} \mathrm{C}$ and $3-5 \mathrm{ml}$ of CSF collected from the cerebellomedullary cistern and frozen at $-80^{\circ} \mathrm{C}$.

The samples were analyzed by ELISA using total antigen from lysed promastigotes. The antigen was prepared from L. chagasi promastigotes. The parasites were grown at $28^{\circ} \mathrm{C}$ in RPMI 1640 (Gibco, Pisley, UK), supplemented with $100 \mathrm{IU} / \mathrm{ml}$ penicillin, 100 $\mu \mathrm{g} / \mathrm{ml}$ streptomycin, $2 \mathrm{mM}$ L-glutamine and $10 \%$ heat-inactivated fetal calf serum (FCS, Gibco). After reaching the stationary phase, the parasites were harvested, washed in phosphate-buffered saline (PBS), and lysed by repetitive freeze-thaw cycles until they were completely disintegrated as determined by microscopic inspection. The protein concentration in the lysed parasites was determined by the bicinchoninic acid protein assay (Pierce, Rockford, IL, USA) (16).

The antigen was coated with $20 \mu \mathrm{g} / \mathrm{ml}$ (17) protein, $\mathrm{pH} 9.6$, then washed three times in PBS containing $0.05 \%$ Tween 20 (washing buffer) and saturated for $1 \mathrm{~h}$ with $150 \mu \mathrm{l} /$ well of a mixture of PBS and 10\% FCS at room temperature. Next, the preparation was washed again three times with washing buffer. Blocking buffer/Tween ( $100 \mu 1$ of serum sample (1/400) or CSF (1/2) diluted in PBS, $\mathrm{pH} 7.4$, containing $0.05 \%$ Tween 20 and $10 \%$ FCS) was added to each well and incubated at room temperature for $3 \mathrm{~h}$, followed by three washes with washing buffer. Subsequently $100 \mu \mathrm{l} /$ well of anti-dog IgG conjugated with horseradish peroxidase (Sigma, St. Louis, MO, USA) at appropriate dilution in blocking buffer/Tween was added, incubated at room temperature for $1 \mathrm{~h}$ and washed. The substrate solution $(0.4 \mathrm{mg} / \mathrm{ml} o$-phenyl- 
enediamine (Sigma) and $0.4 \mu \mathrm{l} / \mathrm{ml} \mathrm{H}_{2} \mathrm{O}_{2}$ in phosphate citrate buffer, $\mathrm{pH}$ 5.0) was added at $100 \mu \mathrm{l} /$ well and developed for $5 \mathrm{~min}$ at room temperature. The reaction was stopped with $50 \mu \mathrm{l}$ of $3 \mathrm{M} \mathrm{H}_{2} \mathrm{SO}_{4}$. Absorbance was measured at $492 \mathrm{~nm}$ using a Titertek Multiskan Plus MK II reader (Flow Laboratories International S.A., Lugano, Switzerland). Negative and positive controls were included on each plate. The positive controls obtained from a hyperimmune animal were included to check the ELISA reaction. The cut-off (serum) was determined using the mean $+3 \mathrm{SD}$ of the readings obtained for serum of healthy dogs $(\mathrm{N}=20)$ from nonendemic leishmaniasis areas (18).

High titers of $L$. chagas $i$ antibodies were detected in serum from animals studied by ELISA. The results (1/400) are reported (Figure 1) as mean absorbance \pm SD (1.939 \pm 0.405 ; negative control, $0.154 \pm 0.074)$. The results were similar in three experiments and the samples were analyzed in triplicate.

The neurological symptoms of visceral leishmaniasis are associated with chronic inflammation of the meninges with lymphocyte and plasma cell infiltrates (15). We investigated whether antibodies in CSF could break the homeostasis among CSF, interstitial fluid and brain, and thus affect brain function.

To detect antibodies in CSF of the same animals, a lower dilution was used $(1 / 2)$ because the protein concentration is very low (14). The cut-off (CSF) was determined using the mean $+3 \mathrm{SD}$ of the readings obtained for the CSF of healthy dogs $(\mathrm{N}=10)$ from nonendemic leishmaniasis areas (18).

The results obtained by ELISA for CSF are shown in Figure 2 and reported as mean absorbance \pm SD $(1.571 \pm 0.532$; negative control, $0.0195 \pm 0.040)$. A high titer of $L$. chagasi antibodies was detected in CSF from infected animals and no association was observed between CSF antibody titer and presence of neurological symptoms.

The antibodies detected in CSF suggest the presence of parasites or antigens in this compartment. The presence of parasites was investigated by immunohistochemistry, but no positive result has been obtained thus far, with only the vessel wall being positive for Leishmania (data not shown). In fact, the presence of parasites in the choroid plexus (12) and inside and outside macrophage in meningitis has been reported in dogs with visceral leishmaniasis (15). We did not observe amastigote forms in any of the CSF

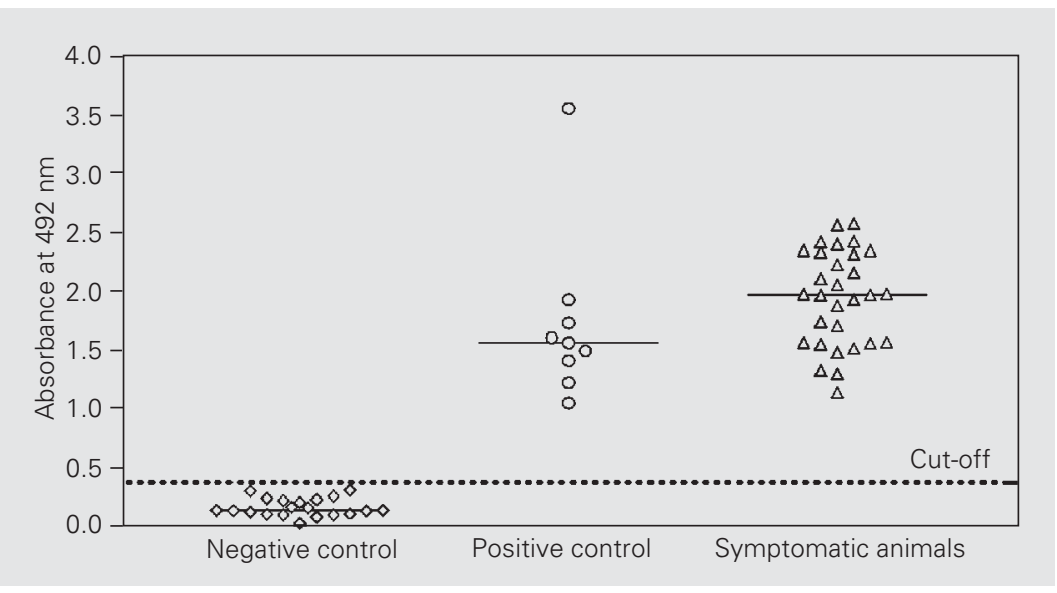

Figure 1. Serum reactivity (IgG) against total antigen of Leishmania chagasi from healthy dogs from nonendemic areas (negative control, $N=20$ ), sera from positive dogs (positive control, $N=9$ ), and sera from dogs with L. chagasi infection diagnosed by cytological analysis $(\mathrm{N}=30)$.

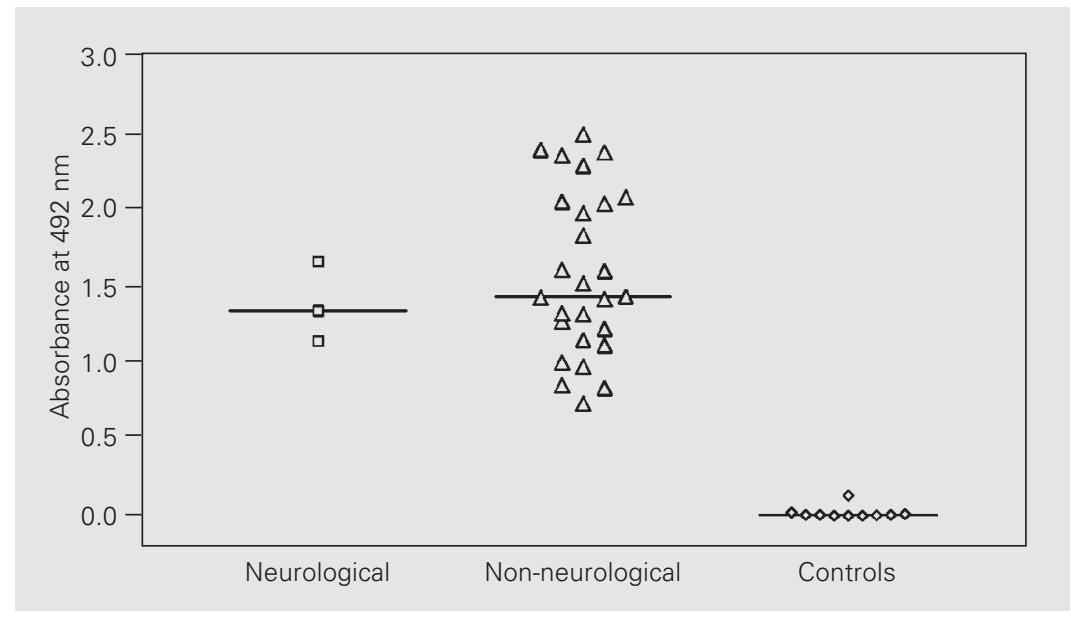

Figure 2. Cerebrospinal fluid reactivity (IgG) against total antigen of Leishmania chagasi from dogs with $L$. chagasi infection with neurological symptoms $(N=3)$ and without neurological symptoms ( $N=27$ ). No statistical difference was observed between the two groups studied (unpaired $t$-test). 
samples studied.

Although plasma cells could be involved in local antibody production, histological analysis did not show an inflammatory reaction in the choroid plexus of any animal studied (data not shown). This suggests that the high antibody levels observed in CSF could have been previously produced in the lymphoid tissue and then have passed through the CNS barrier, thus helping the local immune response in the presence of infection. However, we cannot rule out the possibility that the transfer of leishmania antigens to the CNS might have led to intrathecal antibody production, as observed in malaria cases (19). Other mechanisms might be involved in the disease associated with neurological symptoms.

We investigated CSF total cell count in undiluted samples using a Fuchs-Rosenthal chamber. Differential counts were performed after centrifugation with a REVAN cytocentrifuge, model 2000D, and Rosenfeld staining. The animals with neurological symptoms presented values above normal (mean \pm SD: $52.3 \pm 9.3$ leukocytes $/ \mu 1$ ), which was not observed in the infected animals without neurological symptoms (mean \pm SD: $3.8 \pm$ 1.4 leukocytes/ $\mu 1$ ). We observed a predominance of lymphocytes in the differential cell count.

Lymphocyte reaction is more frequent in neurological diseases. These are the cells of the sub-acute inflammatory phase. They are also the predominant elements in the cytological picture in chronic processes. Lym- phocyte reaction is observed in viral meningitis, in meningoencephalitis, in some CNS parasitoses and in the phase of cryptococcosis evolution (20). Thus, the findings of the differential cytological test of the CSF of dogs with neurological symptoms were compatible with meningoencephalitis caused by leishmania.

All animals studied showed a high level of antibodies in CSF, and some significant correlations were observed between antibodies present in sera and in CSF. This observation suggests that $L$. chagasi can cause breakdown of filtration barriers and the transfer of antibodies and antigens from the blood to the CSF compartment. No correlation was observed between antibody titer in CSF and neurological symptoms.

These data agree with those observed in regard to L. infantum infection (14). Further studies using a large number of samples can clarify if antibodies are involved in this brain tissue disease associated with neurological symptoms.

The observation of $L$. chagasi antibodies in the CSF of dogs is important because dogs could constitute an appropriate model for the analysis of neurological outcome associated with visceral leishmaniasis in humans, opening up an interesting field of research with potential implication for treatment.

\section{Acknowledgments}

We thank Dr. Cáris Maroni Nunes for technical support.

\section{References}

1. Dye C (1996). The logic of visceral leishmaniasis control. American Journal of Tropical Medicine and Hygiene, 55: 125-130.

2. Pinelli E, Killick-Kendrick R \& Wagenaar J (1994). Cellular and humoral immune response in dogs experimentally and naturally infected with Leishmania infantum. Infection and Immunity, 62: 229235.

3. Lopez R, Lucena R, Novales M, Ginel PJ, Martin E \& Molleda JM (1996). Circulating immune complexes and renal function in canine leishmaniasis. Zentralblatt für Veterinaermedizin Reihe B, 43: 469474.
4. Chabanne L, Fournel C, Faure JR, Veysseyre CM, Rigal D, Bringuier JP \& Monier JC (1993). IgM and IgA rheumatoid factors in canine polyarthritis. Veterinary Immunology and Immunopathology, 39: 365379.

5. Pumorola M, Brevik L, Badiola J, Vargas A, Domingo M \& Ferrer $L$ (1991). Canine leishmaniasis associated with systemic vasculitis in two dogs. Journal of Comparative Pathology, 105: 279-286.

6. García-Alonso M, Blanco A, Reina D, Serrano FJ, Alonso C \& Nieto CG (1996). Immunopathology of the uveitis in canine leishmaniasis. Parasite Immunology, 18: 617-623. 
7. Longstaffe JA \& Guy MW (1986). Canine leishmaniasis - United Kingdom update. Journal of Small Animal Practice, 27: 633-671.

8. Keenan CM, Hendricks LD, Lightner L \& Johnson AJ (1984). Visceral leishmaniasis in the German shepherd dog. II. Pathology. Veterinary Pathology, 21: 80-86.

9. Ginel PJ, Mozos E, Fernández A, Martínez A \& Molleda JM (1993). Canine pemphigus foliaceus associated with leishmaniasis. Veterinary Record, 133: 526-527.

10. Longstaffe JÁ, Jefferies AR, Kelly F, Bedford PGC, Herrtage ME \& Darke PGG (1983). Leishmaniasis in imported dogs in the United Kingdom: a potential human hazard. Journal of Small Animal Practice, 24: 23-30.

11. Mugai R, Gatei DG, Shaunak S, Wozniak A \& Bryceson ADM (1983). Jejunal function and pathology in visceral leishmaniasis. Lancet, 27: 476-479.

12. Nieto CG, Viñulas J, Blanco A, García-Alonso M, Verdugo SG \& Navarrete I (1996). Detection of Leishmania infantum amastigotes in canine choroid plexus. Veterinary Record, 139: 346-347.

13. Prasad LSN \& Sem S (1996). Migration of Leishmania donovani amastigotes in the cerebrospinal fluid. American Journal of Tropical Medicine and Hygiene, 55: 652-654.

14. Gárcia-Alonso M, Nieto CG, Blanco A, Requena JM, Alonso C \& Navarrete I (1996). Presence of antibodies in the aqueous humor and cerebrospinal fluid during Leishmania infections in dogs. Patho- logical features at the central nervous system. Parasite Immunology, 18: 539-546.

15. Viñuelas J, García-Alonso M, Ferrando L, Navarrete I, Molano I, Mirón C, Carcelén J, Alonso C \& Nieto CG (2001). Meningeal leishmaniosis induced by Leishmania infantum in naturally infected dogs. Veterinary Parasitology, 101: 23-27.

16. Reed SG, Shreffler WG, Burns Jr JM, Scott JM, Orge MG, Ghalib HW, Siddig M \& Badaro R (1990). An improved serodiagnostic procedure for visceral leishmaniasis. American Journal of Tropical Medicine and Hygiene, 43: 632-639.

17. Riera C, Valladares JE \& Gállego M (1999). Serological and parasitological follow-up in dogs experimentally infected with Leishmania infantum and treated with meglumine antimoniate. Veterinary Parasitology, 84: 33-47.

18. Voller A, Bidwell DE \& Bartlett A (1980). Enzyme-linked immunosorbent assay. In: Rose N \& Friedman H (Editors), Manual of Clinical Immunology. American Society for Microbiology, Washington, DC, USA, 359-371.

19. Finley RW, Mackey LJ \& Lambert PH (1982). Virulent P. berghei malaria: prolonged survival and decrease cerebral pathology in cell dependent nude mice. Journal of Immunology, 129: 2213-2218.

20. Reis JB, Bei A \& Reis Filho FB (1980). Líquido Cefaloraquidiano. Sarvier, São Paulo, SP, Brazil. 